\title{
Analysis of the Urban Heat Island Intensity Based on air Temperature Measurements in a Renovated Part of Budapest (Hungary)
}

\author{
Csenge Dian ${ }^{A^{*}}$, Rita Pongrácz ${ }^{A}$, Dóra Incze ${ }^{A}$, Judit BartholyA ${ }^{A}$ Attila Talamon ${ }^{B}$ \\ Received: October 31, 2019 | Revised: December 28, 2019 | Accepted: December 28, 2019 \\ DOI: $10.5937 / g p 23-23839$
}

\begin{abstract}
The ratio of buildings, streets, and other artificially covered areas are increasing in cities. Ferencváros is an inner district of Budapest, the capital city of Hungary. For the local government of the district it is an important goal in the framework of the urban development planning to increase the proportion of vegetation since green areas have a mitigating effect for the urban heat island (UHI) intensity. We carried out an in situ measurement program for air temperature and relative humidity with 24 measuring points in Ferencváros, and also completed a green area survey in the renovated part of the district. The main aim of this paper is to analyse the daily cycle and the spatial structure of the UHI intensity based on air temperature.
\end{abstract}

Keywords: spatial structure of UHI; daily cycle of UHI intensity; in situ measurements; green area; summer; autumn

\section{Introduction}

Urban climatology is an important research field in climatology nowadays, because more than $54 \%$ of the world's population live in urban and suburban region (United Nations, 2015). This ratio is much higher in Europe, and it is about $70 \%$ in Hungary (Hungarian Central Statistical Office, 2017). Buildings and artificial covers modify the climatic conditions (including energy budget, radiation components and wind conditions) in cities (Marković et al. 2013, Bajšanski et al. 2015). The temperature in the urban areas is higher than in the surrounding rural areas due to the different albedo values of various surface covers and the multiple reflection of radiation by the urban geometry (Oke, 1981). This well-known effect is the urban heat island (UHI), and the temperature difference between the urban and the rural area is defined as the
UHI intensity (Oke, 1973, 1982). Larger and more populous cities show stronger UHI intensities because of the more concentrated artificial covers with more vertical surfaces (Landsberg, 1981).

There are two fundamentally different methods to determine the UHI intensity: (1) surface temperature data from satellite measurements, and (2) in situ air temperature measurements. The major characteristics of UHI (especially the temporal behavior, i.e. intensity during daytime and nighttime) can be different depending of the type of data used in the analysis. Satellite data are typically used for detailed examination of larger areas (e.g. Voogt and Oke, 2003; Tran et al., 2006; Schwarz et al., 2011). This method is customary to analyse the surface urban heat island (SUHI) of Central European cities (e.g. in Czech Republic: Do-

\footnotetext{
A Department of Meteorology, Eötvös Loránd University, Pázmány Péter st. 1/A, H-1117, Budapest, Hungary; diancsenge@caesar. elte.hu; prita@nimbus.elte.hu; incze.dora96@gmail.com; bartholy@caesar.elte.hu

B Centre for Energy Research, 29-33 Konkoly-Thege Miklós Road, H-1121, Budapest, Hungary, talamon.attila@energia.mta.hu

* Corresponding author: Csenge Dian; e-mail: diancsenge@caesar.elte.hu; tel. +36203338649
} 
brovolný, 2013; Geletič et al. 2019; in Romania: Cheval and Dumitrescu, 2015; Herbel et al., 2017; in Hungary: Pongrácz et al., 2010). Nevertheless, the first studies on UHI are based on air temperature measurements. This more traditional UHI definition has been used for decades in urban climatology research (e.g. Klysik and Fortuniak, 1999; Beranová and Huth, 2005; Croitoru et al., 2012; Bokwa et al., 2018). For data collection, urban climate measurement networks can be constructed and should be maintained (Šećerov et al. 2019). Such networks already exist in the Central/ Eastern European region, for example in Novi Sad, Serbia (Savić et al., 2013; Šećerov et al., 2015) and in Szeged, Hungary (Gál et al., 2016). Another possibility to air temperature data acquisition is the use of mobile measurements. These data can be recorded with an instrumented vehicle (e.g. Leconte et al., 2016) or along a pedestrian measurement path (e.g. Tsin et al., 2016). For instance, Lehnert et al. (2018a, 2018b) completed mobile measurements with bicycle in two cities (Brno and Olomouc) of the Czech Republic.

After completing thorough analysis and having sufficient information on the UHI of a specific city, decision makers and local people can act together in order to decrease the negative impacts of UHI. For instance, the UHI effect created by the built-up environment can be mitigated by increasing the vegetation cover within the city since vegetation generally cools its vicinity (Takács et al. 2016; Milošević et al. 2017). The main reason of this cooling effect is the evapotranspiration, which requires energy from the environment, and thus, decrease the heating part of the total emitted energy. The degree of such cooling depends on the type and the structure of the vegetation (Yu and Hien, 2006; Cohen et al., 2012). Recently, more and more local governments have recognised the environmental and sociological benefits of green areas. An effective program associated to this general idea can be identified in Ferencváros (or District IX), one of the total 23 districts of Budapest, Hungary.

Ferencváros is located near the river Danube (Figure 1), it is a very heterogeneous area, includes the southern part of the city centre, residential areas, industrial region and a railway station. Inner and Central Ferencváros (i.e. the northern part of the district) are characterised by 3-4 storey old buildings and block houses. The local government implemented a block rehabilitation program in Central Ferencváros (called Rehabilitation zone), where former old block houses were demolished and green spaces were created inside newly built blocks. In addition, the proportion of vegetation in public areas and parks was also increased (Local Government of Ferencváros, 2010;
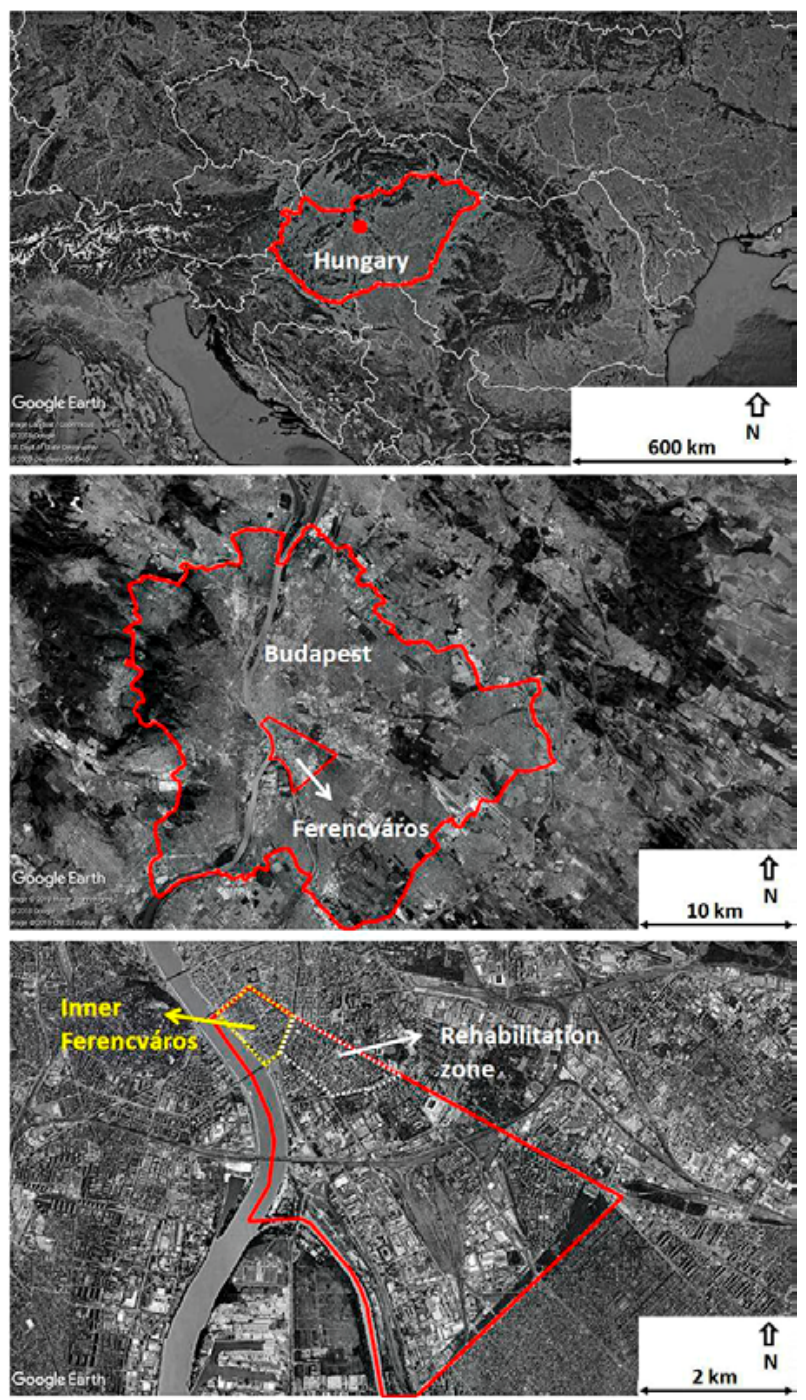

Figure 1. Location of the studied area (Hungary, Budapest, Ferencváros) on Google maps

Source: Google Earth https://earth.google.com/

Budapest Capital Local Government, 2011). These efforts successfully changed the area, and turned it into a highly-valued part of the city. This study aims to analyse the climatic conditions in the current structure of the northern part of Ferencváros. For this purpose, we have launched a mobile measurement program in Inner Ferencváros and the Rehabilitation zone that includes in situ air temperature and relative humidity measurements (Pongrácz et al., 2016). These measurements are used to analyse the UHI intensity in the target area with the main goal of this paper, namely, to examine the temporal and spatial distributions of UHI intensity. Our further plan is to investigate the relationship between air temperature conditions and the ratio of green surfaces and builtup areas, which can be based on the results of survey presented in this paper. 


\section{Green surfaces of the studied area}

The local government completed several block rehabilitation programs starting from the 1980s. Entire blocks were renovated and modified in the most densely built inner part of the district since 1993 in order to create more liveable environment for the citizens. Altogether 220 houses (with $~ 1300$ apartments) were demolished and new buildings were built in their places, moreover, 49 houses (with 1050 apartments) were renovated by today (Local Government of Ferencváros, 2010). In addition to green areas within the blocks, parks were also renovated and vegetation was planted in public areas. Figure 2 shows how the number and spatial extension of green surfaces increased graphical number based on Google Earth satellite imagery (https://earth.google.com/) and maps from the Hungarian Electronic Public Utility System (https:// www.e-epites.hu/e-kozmu), then, they cross-checked the calculated values on the basis of in-situ survey. After having the results of this thorough calculation process, the total area values of the four basic surface cover types in the individual topographical numbers were summed for the blocks within the Rehabilitation Zone. Since this part of the study focuses on the differences between artificial and natural surfaces, Figure 3 shows the natural surface (vegetation and bare soil) ratio (NSR) of the blocks. Two larger parks of the Rehabilitation Zone can be clearly recognised with $100 \%$

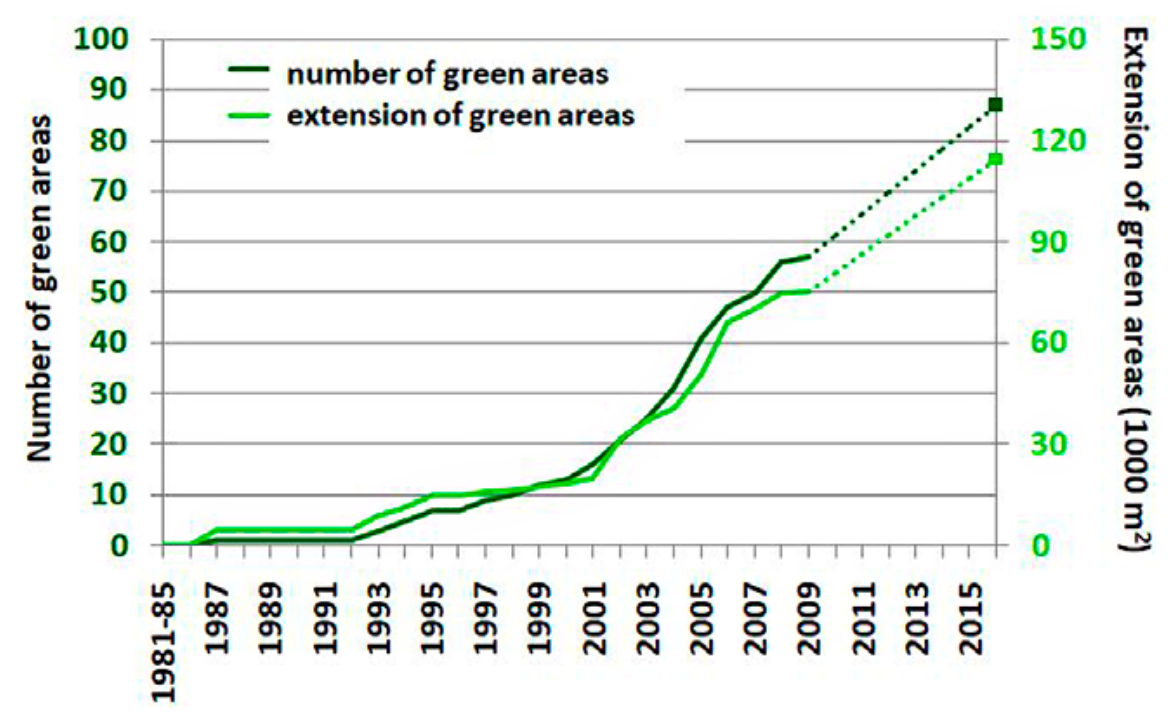

Figure 2. Increase of green areas in Ferencváros, the district IX of Budapest Source: Local Government of Ferencváros, 2010

since the early 1980 s. It can be seen well that the faster increase started around 2000, and both the number and extension of green areas have been sextupled since then.

The students of the Eötvös Loránd University participated in completing a survey of the different surface covers within the Rehabilitation Zone during a summer campaign in 2019. Four basic types of surface cover (i.e. building, other artificial cover, vegetation and bare soil) are defined in this part of the study. Students determined the area of these types for each topo- green area within the corresponding blocks. In addition, natural surface cover exceeds $30 \%$ in more than half of all blocks. In the central and western parts of the Rehabilitation zone natural surfaces cover 30$50 \%$ of individual blocks. The map shows greater variation in the eastern part: blocks are either less green $(\mathrm{NSR}<30 \%)$ or slightly greener $(\mathrm{NSR}=50-60 \%)$ than in the central area. These results confirm that the reintegration of green surfaces into the district is important indeed for the local government, and its efforts already improved the urban environment. 


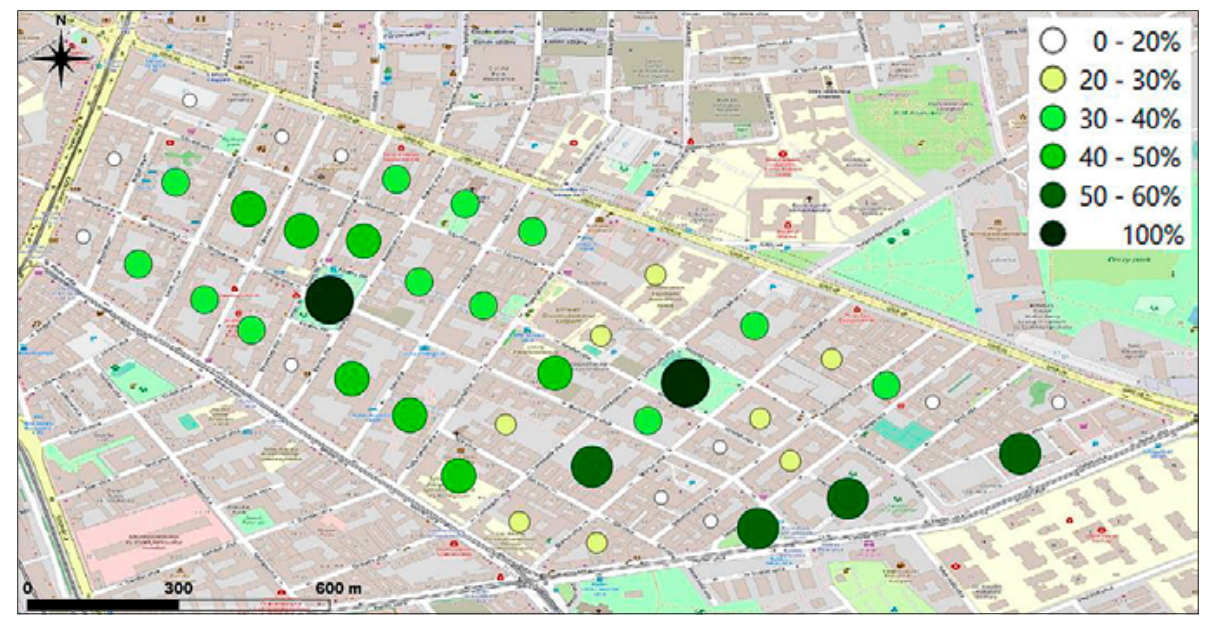

Figure 3. The current proportion of natural surfaces within each block in the Rehabilitation zone based on survey campaign

\section{Meteorological measurements}

An urban measurement program (UMP) was initiated in Inner Ferencváros and the Rehabilitation zone in spring 2015 (Pongrácz et al., 2016) and lasted until autumn 2017. The UMP consisted of mobile measurements (2015-2016) as well as continuous measurements with a frequency of $10 \mathrm{~min}(2015-2017)$ at selected fixed sites. This study focuses on the analysis of mobile measurements that were performed continuously for three days in the middle of summer in 2016, and in autumn for 24 hours starting at $2 \mathrm{pm}$ local time (Table 1). Altogether $\sim 850$ hours of in situ measurements were collected by the students of the Eötvös Loránd University, who walked along a predetermined measuring route, and measured air temperature and relative humidity at 24 measuring points (Figure 4). The measuring points were selected to represent different built-up ratio values within the target area. In order to classify these selected measuring points, we defined five categories (Table 2) that take into account the following three main characteris- tics: distance from buildings, average traffic and vegetation cover (represented by the ratio of vegetation). Category A includes two locations with busy traffic and little vegetation. Five measuring points are located in narrow streets without substantial green areas, and they form category B. Category C (with six measuring points) can be considered as a transition between larger green areas and busy streets. Category D includes six measuring points with substantial vegetation surrounded by buildings. Finally, five parks belong to category $\mathrm{E}$.

The whole measuring route is divided into two parts (Figure 4), the northwestern part in the Rehabilitation zone (from 101 to 113) and the southeastern part in Inner Ferencváros (from 201 to 213). The students walked along these two routes simultaneously starting from $101=201$ and ending at $113=213$, which lasted about 1-1.5 hours. Students met at the last measuring point of the two routes (Boráros square, 113=213), waited until the fellow student(s) arrived from the other route, and then, the measurements were record-

Table 1. Measurement days and the weather situations (dates highlighted with red are used for further analyses because these measurements were completed in anticyclonic periods)

\begin{tabular}{|l|l|}
\hline Measurement days & $\begin{array}{l}\text { Large scale weather situation and the highest temperature in the } \\
\text { synoptic station of Budapest }\end{array}$ \\
\hline 4 July (0-24 CEST) & anticyclone; clear sky; $27^{\circ} \mathrm{C}$ \\
\hline 5 July (0-24 CEST) & anticyclone; clear sky; $26^{\circ} \mathrm{C}$ \\
\hline 6 July (0-24 CEST) & $\begin{array}{l}\text { outer zone of the anticyclone being present in the previous days; partly } \\
\text { cloudy; } 27^{\circ} \mathrm{C}\end{array}$ \\
\hline $22-23$ September (14 CEST-14 CEST) & anticyclone; sunny day with cumulus clouds; $18-20^{\circ} \mathrm{C}$ \\
\hline $29-30$ September (14 CEST-14 CEST) & anticyclone; clear sky; $23-24^{\circ} \mathrm{C}$ \\
\hline $13-14$ October (14 CEST-14 CEST) & outer zone of an anticyclone; partly cloudy; $11^{\circ} \mathrm{C}$ \\
\hline $27-28$ October (14 CEST-14 CEST) & anticyclone; cloudy around midnight; $10-11^{\circ} \mathrm{C}$ \\
\hline $\begin{array}{l}10 \text { November (14 CET-24 CET, measurements were } \\
\text { stopped due to rain) }\end{array}$ & outer zone of a midlatitude cyclone; cloudy and later rainy; $4{ }^{\circ} \mathrm{C}$ \\
\hline $17-18$ November (14 CET-14 CET) & outer zone of an anticyclone; cloudy; $3-8{ }^{\circ} \mathrm{C}$ \\
\hline
\end{tabular}


ed along the same two routes but in reverse order (i.e. starting from $113=213$, and ending at $101=201$ ). Obviously, the measurements at the different points were recorded at different times, therefore, temporal averaging was needed. For this purpose, we paired two subsequent values of air temperature data from a specific measuring point, and we calculated the averages of all pairs. In addition to calculating these temperature averages, time averages (forming virtual time when no real measurement was recorded) were also determined, thus assuming a linear temporal behavior of temperature change in the scale of 1-2 hours. As a result, the spatial distribution of temperature can be determined in the target area for the virtual times.

The measurements were performed with a portable handheld Testo-635 sensor and recorded with a data logger connected to it. The accuracy of the temperature sensor is $\pm 0.3{ }^{\circ} \mathrm{C}$ (Testo 635 - https://www.testo.com/ en/testo-635-1/p/0560-6351). The sensor was placed in a shaded area near a height of $2 \mathrm{~m}$, at each measuring point. For calculating the UHI intensity, temperature measurements were compared to the hourly recorded data of the main synoptic station (ID number: 12843) of Budapest that is located in the southeastern suburb part of Budapest (Synop riports: http://www.ogimet. com/synops.phtml.en).The UHI intensity is stronger in anticyclonic weather conditions, therefore, the results are presented for these measurement periods: 4-6 July, 22-23 September, 29-30 September and 27-28 October (Table 1). These days were mostly calm and clear with daily maximum temperature of $26-27^{\circ} \mathrm{C}, 18-20^{\circ} \mathrm{C}, 23-$ $24^{\circ} \mathrm{C}, 10-11{ }^{\circ} \mathrm{C}$, respectively.

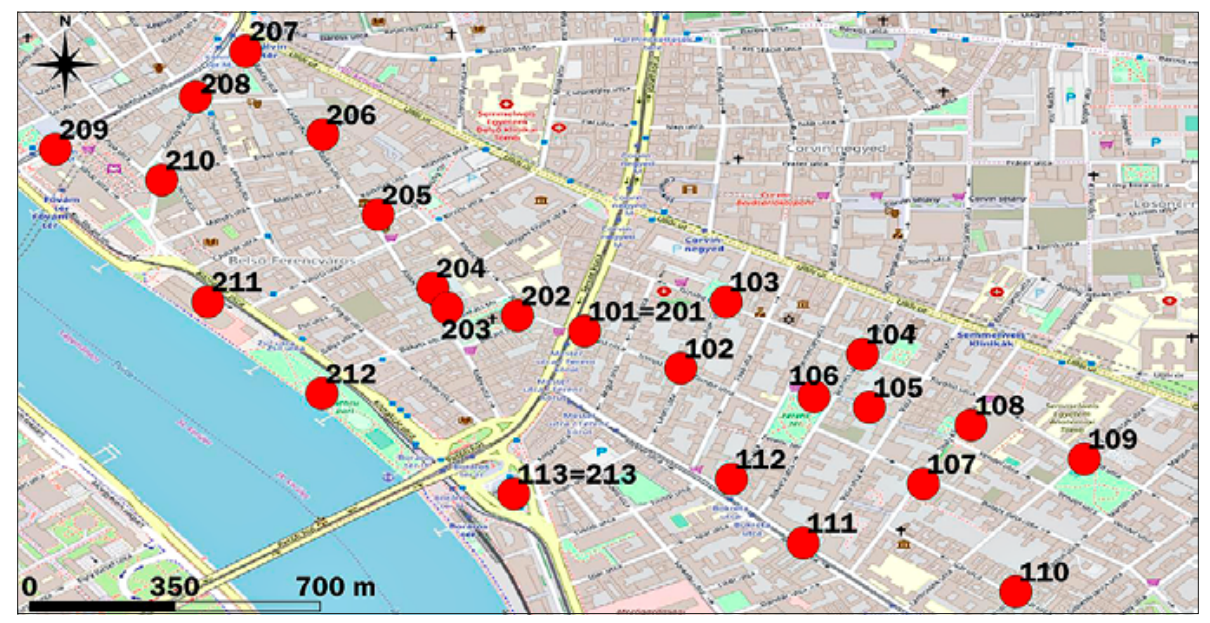

201: Ferenc blvd. / Tompa st. (C)

202: Bakáts sq. / Tompa st. (E)

203: Bakáts sq. / Ráday st. (E)

204: Ráday st. 42 (D)

205: Ráday st. / Biblia st. (B)

206: Ráday/Erkel st. (B)

207: Kálvin sq. (A)

208: Lónyay st. / Gönczy st. (C)

209: Vámház blvd., Market Hall (C)

210: Csarnok sq. (D)

211: Building Bálna (C)

212: Nehru Park (E)

213: Boráros sq. (A)

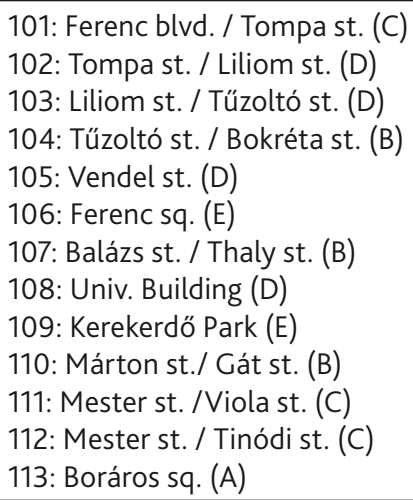

Figure 4. Measuring routes 101 to 113 and 201 to 213 with the locations of measuring points (built-up ratio category is indicated in parentheses) 
Table 2. Classification of measuring points based on their environmental characteristics from in-situ survey

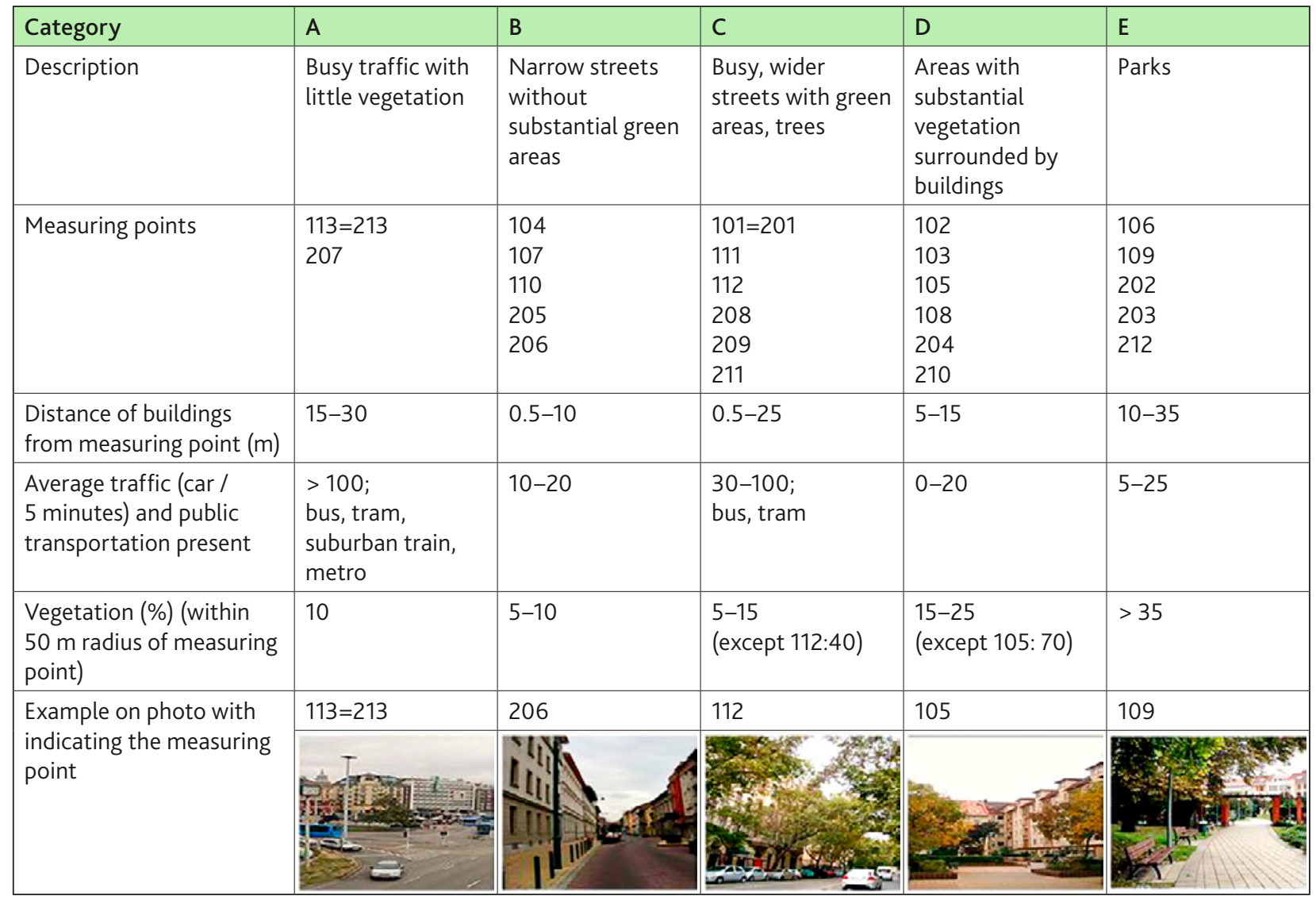

\section{Results and discussion}

The present UHI analysis includes temporal aspects as well as spatial aspects. First, the UHI intensity is evaluated in each measuring point throughout the entire day. Then, the UHI intensities are analysed within the target area, namely, how the individual measuring sites differ from the overall average of the measuring route at specific times of the day.

\section{Analysing the daily distribution of $\mathrm{UHI}$ intensity}

The temporal analysis starts with determining the daily cycle of UHI intensity for each of the five defined categories within the target area that enables us to evaluate the effects of different environmental characteristics. Moreover, daily UHI intensity distributions are summarised separately for summer and autumn measurements, which allows the seasonal differences to be identified. For this purpose air temperature measurements were used both for summer and for autumn in calm anticyclonic weather conditions (summer: 4-5 July; autumn: 22-23 September, 29-30 September, and 27-28 October). The temporal distributions of UHI intensities are obtained by (i) averaging the pairs of subsequent in situ air temperature measurements in each measuring point of the target area, and then (ii) comparing these to the corresponding temperature measured at the synoptic station of Budapest. The daily cycle is assumed to follow a polynomial trendline, so several orders of polynomial curves were fitted to the UHI intensity values throughout the day (the total number of available values within time series is N). The best polynomial assumption should be selected among the various possibilities by comparing them to each other.

The optimal $p$ degree from the various polynomial curves can be determined by using the Akaike (1974) Information Criterion (AIC):

$$
(p)=-2 \cdot \ln (L)+2 \cdot p
$$

where $L$ is the maximum value of the likelihood function and $p$ is the number of independent parameters that can be fitted to the time series of observations. On the one hand, perfect fit is assured by using $p=N$. This assumption is lacking the capability of characterising the general behavior of UHI intensity on the other hand, and cannot conclude to typical daily cycles. AIC represents the goodness of fit via the likelihood function, however, it also includes 
a penalty increasing with $\mathrm{p}$. Thus, the lower the value of $\operatorname{AIC}(p)$, the more unlikely that overfitting occurs in the polynomial approach.

The evaluation of AIC shows that $p=3$ for most measuring stations in the target area of this study, thus, the daily cycle of UHI intensity can be described with a cubic polynomial trend. The specific polynomial functions are determined for all measuring points, then, typical examples are selected to represent the individual categories. Figure 5a-e shows typical daily UHI intensity cycles in summer for the five categories. Overall, these cycles are quite similar in the terms of general shape, nevertheless, slight differences can be recognised in the amplitude of daily cycles. The maximum UHI intensities were observed between midnight and 3 a.m., which is consistent with other studies (e.g. Oke, 1995; Lelovics et al. 2016). Furthermore, lower UHI intensities occurred at daytime than at night (note that sunrise and sunset occurred at 4:53 and 20:43 CEST, respectively, at the beginning of July). The maximum values of the fitted polynomial trendlines are in the range of $2.5-3.5^{\circ} \mathrm{C}$, whereas the highest actual UHI intensity values in the middle of the night exceeded $4.5^{\circ} \mathrm{C}$ in category $\mathrm{C}$ (i.e. busy, wider streets with green areas, trees). Lower UHI intensity values occurred in category E (i.e. parks) where heat storage from daytime incoming solar radiation is less effective due to the presence of vegetation. In addition, the amplitude of the fitted polynomial trendline is clearly smaller in category $\mathrm{E}$ than in other categories (especially $\mathrm{C}, \mathrm{B}$, and $\mathrm{A}$ ).

The typical daily cycles of UHI intensity in autumn (Figure $5 \mathrm{f}-\mathrm{j}$ representing each of the five defined categories) are generally similar to the daily cycles in sum-
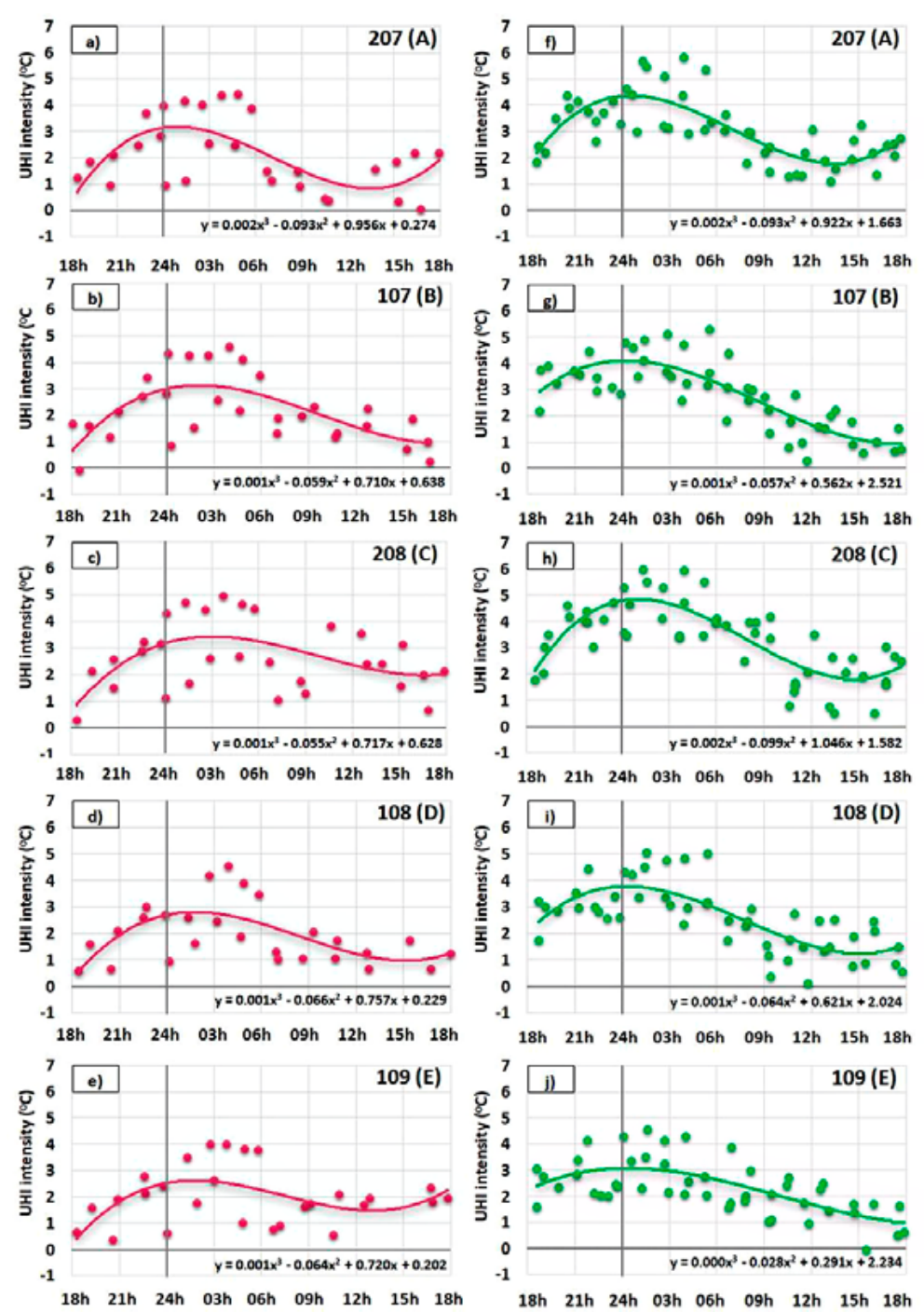

Figure 5. The daily cycle of UHI intensity in summer (left, a-e) and in autumn (right, $\mathrm{f}-\mathrm{j}$ ) for selected measuring points (one from each of the five categories). Third degree polynomial trends are fitted to data series, and the resulted curves are shown together with their formulas (at the bottom of the diagrams) for all categories 
mer. However, the maximum values were higher in autumn (namely, in the range of $3-5^{\circ} \mathrm{C}$ ) than in summer. Similarly to summer, the greatest difference occurred between category $\mathrm{C}$ and category $\mathrm{E}$, but the intensity difference in autumn $\left(\sim 2{ }^{\circ} \mathrm{C}\right)$ is twice as much as in summer $\left(\sim 1^{\circ} \mathrm{C}\right)$, which also implies a greater amplitude in autumn than in summer. Another slight difference between autumn and summer is that the maximum of the daily cycle in autumn occurred closer to midnight, i.e. it shifts earlier compared to summer due to the longer autumn nights with earlier sunsets.

\section{Analysing the spatial structure of UHI intensity}

We added a spatial aspect to the temporal analysis of UHI intensity in this study, and thus investigated the spatial structure of UHI intensity. For this purpose, first, we determined the UHI intensities for each measuring point relative to the synoptic station of $\mathrm{Bu}-$ dapest at virtual times as it is described in section Meteorological measurements. Thereafter the averaged UHI intensity of the 24 measuring points was determined for each virtual time interval (a 24-member set of virtual times from individual measuring points form a $\sim 5-10$-minute-long interval due to the inhomogeneous speed along the route), and hence the UHI intensity anomalies (i.e. differences between the actual UHI intensities in the measuring points and the route-average UHI intensity) were calculated for each measuring point. Thus, the resulting spatial structures can be evaluated after mapping the UHI intensity anomaly values for each available virtual time. Among the map series created with QGIS eight maps (shown in Figure 6) were selected from two 24h-long measuring period, one in summer (5-6 July) and another one in autumn (29-30 September). Four virtual times are used to illustrate changes in spatial structure during the day: late afternoon (17h in summer and $18 \mathrm{~h}$ in autumn), midnight (24h in both seasons), morning (o6h in both seasons), and noon (12h in both seasons). Note the difference between the late afternoon virtual times in summer and in autumn. This is due to the fact that the walking along the entire measuring route lasted about 2-3 hours depending on walking speed, thus the averaged virtual times do not always represent the same hour. So $17 \mathrm{~h}$ and $18 \mathrm{~h}$ virtual time is available from 5 July and 29 September, respectively. All the other three virtual times are considered the same. On the basis of the anomaly map series from early-July and from late-September shown in Figure 6, the following main characteristics can be summarised for the daily cycle of the spatial patterns of the UHI anomaly.

(i) In general, the daily cycles of the two seasons are quite similar.

(ii) Late afternoon, $17-18 \mathrm{~h}$ :

- The three warmest measuring points within the target area are mostly covered by artificial materials, and they are from the environmental categories with busy traffic $(\mathrm{A}: 113=213$, and C: $102=$ $201,111)$ both in summer and in autumn.

(iii) Midnight, 24h:

- The UHI intensities near the Danube were lower than the other parts of the target area because of the cooling effect of the river, which can be recognised even at the built-up measuring point $(113=213)$ from category A.

- The other measuring points in Inner Ferencváros were warmer compared to the average $\mathrm{UHI}$ intensity of the area; in contrast, the UHI intensity anomalies were negative in the Rehabilitation zone, probably reflecting the overall favorable effect of higher green proportions within the blocks.

- The smallest spatial difference of UHI intensity within the target area can be detected at midnight although the average UHI intensity along the entire route is the highest $\left(3.57^{\circ} \mathrm{C}\right.$ in summer and $3.95^{\circ} \mathrm{C}$ in autumn) among the four parts of the day. The intensity anomalies form a $\sim 2{ }^{\circ} \mathrm{C}$ temperature interval (from $-1{ }^{\circ} \mathrm{C}$ to $1{ }^{\circ} \mathrm{C}$ ).

(iv) Morning, o6h:

- The spatial patterns of UHI intensities are quite similar to the results of midnight. However, the relative cooling effect of the Danube is slightly stronger in summer than in autumn.

(v) Noon, 12h:

- The greatest spatial difference of the UHI intensities occurred at noon $\left(\sim 3.5^{\circ} \mathrm{C}\right.$ between measuring points $113=213$ and 211 , in autumn). The reason of this lies in the different warming of the various surfaces due to solar radiation.

- The difference between summer and autumn is also substantial compared to the other parts of the day. The average UHI intensity is $\sim{ }^{\circ} \mathrm{C}$ in autumn (which is the smallest among the four parts of the day), and exceeds $2{ }^{\circ} \mathrm{C}$ in summer (which is greater than in late afternoon). 

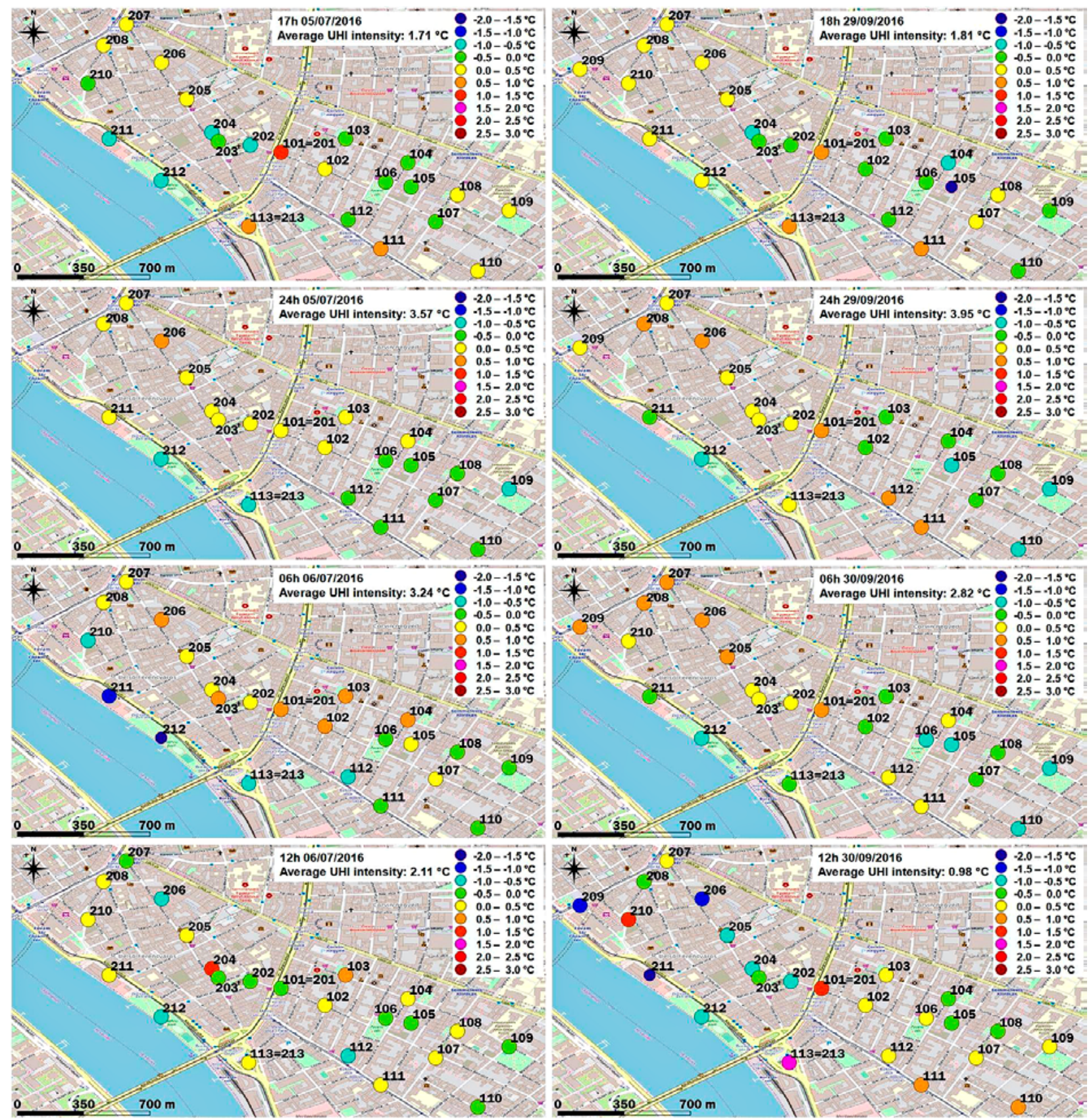

Figure 6. The daily cycle of spatial patterns of UHI intensity anomaly relative to the average UHI intensity of the entire route, 5-6 July 2016 (left) and 29-30 September (right). (Measuring point 209 was added after the summer campaign, that is why it is missing from the maps of July.)

\section{Conclusion}

The local government of Ferencváros recognised the importance of increasing vegetation, i.e. green surfaces in the city center. Therefore, in order to create a more liveable environment for citizens, different renovation programs were completed in the district. The efforts of the local government resulted in the substantial increase of green areas (both the number and extension increased sixfold between 2000 and 2016), with above $30 \%$ of green surfaces in the majority of the blocks in the Rehabilitation zone by today.

The continuous 24-hour-long, air temperature measurement campaigns organised in the summer (July) and autumn (September-November) of 2016 allow us to analyse the daily cycle and spatial structure of UHI intensity in the target area located in the northwestern part of Ferencváros. The following con- 
clusions can be drawn on the basis of the presented results:

(1) The analysis of the daily cycle of UHI demonstrated clearly that the maximum UHI intensity generally occurs 3-6 hours after sunset (in the case of calm weather with anticyclonic conditions). This maximum develops between midnight and 3 a.m. in summer, with the average intensity values of $2.5-$ $3.5^{\circ} \mathrm{C}$. The maximum UHI intensity is higher in autumn (by $\sim 1{ }^{\circ} \mathrm{C}$ ), and shifts earlier (to the period between 9 p.m. and midnight) due to the earlier sunsets. The UHI intensities decrease during the daytime.

(2) In addition to this temporal aspect, we also analysed the spatial structure of UHI intensity based on the anomaly relative to the average intensity of the whole target area. This part of the study showed only slight seasonal differences in the spatial structure of UHI. Spatial differences within the target area are the smallest at night when the average UHI intensity reaches its maximum, while the greatest differences occurred at daytime with much smaller average UHI intensity values. Consequently, the local effects due to the surface cover (i.e. vegetation and artificial cover) are more relevant at daytime.

We are planning to continue the in-situ urban climate measurement program as well as further develop the green surface and building surveys. The connection of their results will allow more detailed analysis of the relationship between the built environment and the UHI effect.

\section{Acknowledgement}

Research leading to this paper has been supported by the following sources: the Hungarian National Research, Development and Innovation Fund under grants K-129162, K-120605 and K-109109, the Hungarian Ministry of Human Capacities under the ELTE Excellence Program (grant number: 783-3/2018/FEKUTSRAT), and the Széchenyi 2020 programme, the European Regional Development Fund and the Hungarian Government via the AgroMo project (GINOP-2.3.2-15-2016-0028). In-situ measurements were completed by BSc and MSc students of the Eötvös Loránd University.

\section{References}

Akaike, H. (1974). A new look at the Statistical Model Identification. IEEE Transactions on Automatic Control, 19, 716-723. doi: 10.1109/TAC.1974.1100705

Bajšanski, I., Milošević, D., \& Savić, S. (2015). Evaluation and improvement of outdoor thermal comfort in urban areas on extreme temperature days: Applications of automatic algorithms. Building and Environment, 94, 632-643. doi:10.1016/j.buildenv.2015.10.019

Beranová, R. \& Huth, R. (2005). Long-term changes in the heat island of Prague under different synoptic conditions. Theoretical and Applied Climatology, 82, 113-118. doi: 10.1007/s00704-004-0115-y

Bokwa, A., Dobrovolný, P., Gál, T., Geletič, J., Gulyás, Á., Hajto, M.J., Holec, J., Hollósi, B., KielarI, R., Lehnert, M., Skarbit, N., Štastný, P., Švec, M., Unger, J., Walawender, J.P. \& Žuvela-Aloise, M. (2018). Urban Climate in Central European Cities and Global climate change. Acta climatologica, 51-52,7-35. doi: 10.14232/acta.clim.2018.52.1

Budapest Capital Local Government (2011). Urban development strategy of Budapest. Budapest, $287 \mathrm{p}$.

Cheval, S. \& Dumitrescu, A. (2015). The summer surface urban heat island of Bucharest (Romania) retrieved from MODIS images. Theoretical and Applied Climatology, 121, 631-640. doi: 10.1007/soo704-014-1250-8
Cohen P., Potchter O. \& Matzarakis A., 2012. Daily and seasonal climatic conditions of green urban open spaces in the Mediterranean climate and their impact on human comfort. Building and Environment 51, 285-295. doi: 10.1016/j.buildenv.2011.11.020

Croitoru, A.E., Holobaca, I.H., Lazar, C., Moldovan, F., \& Imbroane, A. (2012). Air temperature trend and the impact on winter wheat phenology in Romania. Climatic Change, 111, 393-410. doi: 10.1007/ s10584-011-0133-6

Dobrovolný, P. (2013). The surface urban heat island in the city of Brno (Czech Republic) derived from land surface temperatures and selected reasons for its spatial variability. Theoretical and Applied Climatology, 112, 89-98. doi: 10.1007/soo704-012-0717-8

Electronic Public Utility System: https://www.e-epites. hu/e-kozmu

Gál T., Skarbit N., \& Unger J. (2016). Urban heat island patterns and their dynamics based on an urban climate measurement network. Hungarian Geographical Bulletin, 65(2), 105-116. doi: 10.15201/hungeobull.65.2.2

Geletič, J., Lehnert, M., Savić, S. \& Milošević, D. (2019). Inter-/intra-zonal seasonal variability of the surface urban heat island based on local climate zones in three central European cities. Build- 
ing and Environment, 156, 21-32. doi: 10.1016/j.buildenv.2019.04.011

Google Earth: https://earth.google.com/

Herbel, I., Croitoru, A. E., Rus, A. V., Roșca, C. F., Harpa, G. V., Ciupertea, A. F., \& Rus, I. (2017). The impact of heat waves on surface urban heat island and local economy in Cluj-Napoca city, Romania. Theoretical and Applied Climatology, 133, 681-695. doi: 10.1007/s00704-017-2196-4

Hungarian Central Statistical Office, Hungary 2017: https://www.ksh.hu/.http://www.ksh.hu/docs/hun/ xftp/terstat/2017/03/06 ts570304.pdf.

Klysik K. \& Fortuniak K. (1999). Temporal and spatial characteristics of the urban heat island of Lódz, Poland. Atmospheric Environment, 33, 3885-3895. doi: 10.1016/S1352-2310(99)00131-4

Landsberg, H. E. (1981). The Urban Climate. Academic Press, pp. 275. doi: 10.1002/qj.49710845719

Leconte, F., Bouyer, J., Claverie, R., \& Pétrissans, M. (2015). Using Local Climate Zone scheme for UHI assessment: Evaluation of the method using mobile measurements, Building and Environment, 83, 3949. doi: 10.1016/j.buildenv.2014.05.005

Lehnert, M., Geletič, J., Dobrovolný, P., \& Jurek, M. (2018a). Temperature differences among local climate zones established by mobile measurements in two central European cities. Climate Research, 75(1), 53-64. doi: $10.3354 /$ cro1508

Lehnert, M., Kubeček, J., Geletič, J., Jurek, M., \& Frajer, J. (2018b). Identifying hot and cool spots in the city centre based on bicycle measurements: the case of Olomouc, Czech Republic. Geographica Pannonica, 22(4), 230-240 doi: 10.5937/gp22-19750

Lelovics, E., Unger, J., Savić, S., Gál, T., Milošević, D., Gulyás, Á., Marković, V., Arsenović, D., \& Gál, CV. (2016). Intra-urban temperature observations in two Central European cities: a summer study. Idojárás, 120, 3, 283-300.

Local Government of Ferencváros (2010). Rehabilitation of Budapest Ferencváros. Budapest. 8o.

Marković, V., Savić, S., Arsenović, D., Stankov, U., \& Dolinaj, D. (2013). Quantification of artificial surfaces impact on urban heat island of Novi Sad (Vojvodina, Serbia). Geographica Pannonica, 17(3), 69-73.

Milošević, D., Bajšanski, I., \& Savić, S. (2017). Influence of changing trees locations on thermal comfort on street parking lot and footways. Urban Forestry and Urban Greening, 23, 113-124. doi: 10.1016/j. ufug.2017.03.011

Oke, T.R. (1973). City size and the urban heat island. Atmospheric Environment, 7, 769-779. http://www.theurbanclimatologist.com/uploads/4/4/2/5/44250401/post6oke1973uhiscaling.pdf

Oke, T. R. (1981). Canyon geometry and the nocturnal urban heat island: comparison of scale model and field observations. Journal of Climatology, 1, 237-254. doi: 10.1002/joc.3370010304

Oke, T.R. (1982). The energetic basis of the urban heat island. Quarterly Journal of the Royal Meteorological Society, 108, 1-24. doi: 10.1002/qj.49710845502

Oke, T. R. (1995). The heat island of the urban boundary layer: characteristics, causes and effects. In: Wind Climate in Cities. Springer Science + Business Media, Dordrecht. 81-107.

Pongrácz R., Bartholy J., \& Dezső Zs. (2010). Application of remotely sensed thermal information to urban climatology of Central European cities. Physics and Chemistry of the Earth, 35, 95-99. doi: 10.1016/j. pce.2010.03.004

Pongrácz, R., Bartholy, J., Dezső, Zs., \& Dian, Cs. (2016). Analysis of the air temperature and relative humidity measurements in the Budapest Ferencváros District. Hungarian Geographical Bulletin, 65(2), 93-103. doi: 10.15201/hungeobull.65.2.1

Savić, S., Unger, J., Gál, T., Milošević, D., \& Popov, Z. (2013). Urban heat island research of Novi Sad (Serbia): A review. Geographica Pannonica, 17(1), 32-36. ISSN 0354-8724 (hard copy) | ISSN 1820-7138 (online)

Schwarz, N., Lautenbach, S., \& Seppelt, S. (2011). Exploring indicators for quantifying surface urban heat islands of European cities with MODIS land surface temperature. Remote Sensing of Environment, 115, 3175-3186. doi: 10.1016/j.rse.2011.07.003

Šećerov, I., Savić, S., Milošević, D., Marković, V., \& Bajšanski, I., (2015). Development of an Automated Urban Climate Monitoring System in Novi Sad (Serbia). Geographica Pannonica, 19(4), 174-183. doi: 10.5937/GeoPan1504174S

Šećerov, I.B., Savić, S.M., Milošević, D.D., Arsenović, D.M., Dolinaj, D.M., \& Popov, S.B. (2019). Progressing urban climate research using a high-density monitoring network system. Environmental Monitoring and Assessment, 191, 89. doi: 10.1007/s10661019-7210-0

Synop riports: http://www.ogimet.com/synops.phtml.en

Takács, Á., Kiss, M., Gulyás, Á., Tanács, E., \& Kántor, N. (2016). Solar permeability of different tree species in Szeged, Hungary. Geographica Pannonica, 20(1), 32-41 doi: 10.5937/GeoPan1601032T

Testo 635 - https://www.testo.com/en/testo635-1/p/0560-6351

Tran, H., Uchihama, D., Ochi, S., \& Yasuoka, Y. (2006). Assessment with satellite data of the urban heat island effects in Asian mega cities. International Journal of Applied Earth Observation and Geoinformation, 8, 34-48. doi: 10.1016/j.jag.2005.05.003

Tsin, P.K., Knudby, A., Krayenhoff, E.S., Ho, H.C., Brauer, M., \& Henderson, S.B. (2016). Microscale mobile monitoring of urban air temperature. Urban Climate, 18, 58-72. doi: 10.1016/j.uclim.2016.10.001 
Analysis of the Urban Heat Island Intensity Based on air Temperature Measurements

in a Renovated Part of Budapest (Hungary)

United Nations (2015). World Urbanization Prospects: The 2014 Revision, (ST/ESA/SER.A/366). U.N. Dept. of Economic and Social Affairs, Population Division, 517. https://esa.un.org/unpd/wup/Publications/Files/WUP2014-Report.pdf
Voogt J. A., \& Oke T. R. (2003). Thermal remote sensing of urban climate. Remote Sensing of Environment, 86, 370-384. doi: 10.1016/So034-4257(03)ooo $79-8$

Yu C., \& Hien W.N. (2006). Thermal benefits of city parks. Energy and Buildings, 38, 105-20. doi: 10.1016/j.enbuild.2005.04.003 